\title{
The role of animal movement, including off-farm rearing of heifers, in the interherd transmission of multidrug-resistant Salmonella
}

\author{
B. Adhikari, ${ }^{\star}$ T. E. Besser,† J. M. Gay, ${ }^{\star}$ L. K. Fox, ${ }^{*}$ M. A. Davis, $†$ R. N. Cobbold, $\ddagger$ A. C. B. Berge, ${ }^{*}$ \\ and D. D. Hancock*1 \\ *AAHP, Field Disease Investigation Unit, Department of Veterinary Clinical Sciences, Washington State University, Pullman 99164 \\ †Department of Veterinary Microbiology and Pathology, Washington State University, Pullman 99164 \\ $\ddagger$ School of Veterinary Science, The University of Queensland, Brisbane, Queensland 4072, Australia
}

\section{ABSTRACT}

Fifty-nine commercial dairy farms were sampled 7 times over 15 to 21 mo to determine the role of animal movement, including off-farm rearing of heifers, in the interherd transmission of multidrug-resistant (MDR) Salmonella spp. Farm management data were collected by on-site inspections and questionnaires on herd management practices before and after the study. Forty-four percent $(26 / 59)$ of herds did not acquire any new MDR Salmonella strains. The number of newly introduced MDR Salmonella strains acquired by the remaining $56 \%$ $(33 / 59)$ of herds ranged from 1 to 8 . Logistic regression models indicated that off-farm heifer raising, including contract heifer raising where heifers commingle with cattle from other farms [commingled heifers, odds ratio $(\mathrm{OR})=8.9,95 \%$ confidence interval (CI): 2.4, 32.80], and herd size per 100-animal increment (herd size, OR $=1.04,95 \% \mathrm{CI}, 1.01,1.05$ ) were significantly associated with the introduction of new MDR Salmonella strains. The negative binomial regression similarly revealed that commingled heifers [relative risk $(\mathrm{RR})=2.3,95 \%$ CI: $1.1,4.7]$, herd size per 100 animals $(\mathrm{RR}=1.02,95 \%$ CI, 1.01, 1.03), and a history of clinical salmonellosis diagnosed before the study $(\mathrm{RR}=2.5,95 \% \mathrm{CI}, 1.3,5.0)$ were significantly associated with the number of new MDR Salmonella strains that were introduced. Factors not associated with the introduction of new MDR Salmonella strains were housing of heifers and cows in the same close-up pen, a common hospital-maternity pen, and the number of purchased cattle. This study highlights the role of animal movement in the interherd transmission of MDR Salmonella spp.

Key words: multidrug-resistant Salmonella, dairy farm, herd-level risk factor

Received June 27, 2008.

Accepted February 3, 2009.

${ }^{1}$ Corresponding author: hancock@wsu.edu

\section{INTRODUCTION}

An estimated 1.4 million human salmonellosis cases and over 500 associated deaths occur annually in the United States (Mead et al., 1999; ERS/USDA, 2001). Salmonella enterica is often found in livestock and poultry, including dairy cattle. Nontyphoidal salmonellosis can result from infection by numerous Salmonella serovars, which are often transmitted via contaminated meat and milk (Mazurek et al., 2004; CDC, 2006; Van Kessel et al., 2007) or through direct contact with infected dairy cattle (Wall et al., 1994; Besser et al., 1997; Calvert et al., 1998). Because most infections result in asymptomatic or self-limiting diarrhea, antibiotics should be used only in immunocompromised patients and cases of systemic salmonellosis (Ruiz et al., 2004). Multidrug-resistant (MDR) Salmonella strains can further complicate the treatment of human cases of salmonellosis (Butaye et al., 2006).

Increasing travel and global trade may facilitate the introduction of new Salmonella serovars into importing countries. Reports of emerging MDR Salmonella strains and global spread have been documented (Hancock et al., 2000; Davis et al., 2007). In particular, inter-farm transmission may be a key element in the epidemiology of MDR Salmonella. Some investigators have suggested that the spread of emerging MDR Salmonella between regions is due to international travel and trade (Davis et al., 1999) and is facilitated by the use of antimicrobials. Transmission of non-foodborne Salmonella infection may be attributed to contact with animals, contaminated water, or the environment (Wall et al., 1995; Besser et al., 2000; Fey et al., 2000; Rice et al., 2003; Hendriksen et al., 2004). Previous studies indicated that wild birds and hedgehogs can play a role in the transmission of salmonellosis (Søbstad et al., 2000; Handeland et al., 2002; Boqvist and Vågsholm, 2005) but little is known about the extent of their influence on Washington State dairies. Risk factors have been identified in the transmission of MDR Salmonella between farms. Introduction of newly purchased cattle to 
Table 1. Management-related data from participating farms

\begin{tabular}{l}
\hline Questions related to farm management \\
\hline 1. $\quad$ Numbers of cattle in the following categories: \\
Lactating cows \\
Dry cows \\
Calves $<3$ mo of age raised on premises \\
Calves $<3$ mo of age raised off premises \\
Heifers $3-20$ mo raised on premises \\
Heifers $3-20$ mo raised off premises \\
Heifers 20 mo to calving raised on premises \\
How many cattle of following types were purchased during the study period? \\
$\quad$ Number of cows (lactating and dry) \\
$\quad$ Number of bulls \\
$\quad$ Number of calves \\
Did any off-farm raised calves and heifers commingle with cattle from other sources? \\
Have any salmonellosis cases been diagnosed during the 3 yr before the start of the study? \\
Are heifers and cows in the same close-up pen? \\
6. Where do cows calve? \\
7. Are any other cows in contact with maternity cows in this location (e.g., sick cows)? \\
8. Where are cows moved after calving? \\
9. $\quad$ Are any other cows in contact with postpartum cows at this location (e.g., sick cows)? \\
\hline
\end{tabular}

the farm has been reported as one of the primary routes of Salmonella transmission (Evans, 1996; Zansky et al., 2002; Vanselow et al., 2007). Some evidence suggests that off-farm raising of heifer calves presents a similar risk of introduction (Hegde et al., 2005). Approximately $12.5 \%$ of US dairy farms send their heifer calves offfarm to be reared at dedicated contracted calf ranches where the heifers are commingled with other animals from source facilities (Wolf, 2003; USDA, 2007).

During the last decade there has been an alarming increase in the appearance of antibiotic-resistant Salmonella that may be a consequence of selective pressure associated with the use of antimicrobial agents in food animals (Varma et al., 2005). Increased morbidity and mortality may result in an inability to treat salmonellosis due to antimicrobial resistance. Investigators have also reported that antimicrobial-resistant strains may be more virulent and cause more prolonged or more severe illness than antimicrobial-susceptible strains (Travers and Barza, 2002). The purpose of this study was to determine the role of animal movement, including offfarm rearing of heifers, in the interherd transmission of MDR Salmonella spp.

\section{MATERIALS AND METHODS}

\section{Study Farms}

Sixty commercial dairy farms in Washington State were enrolled into the study using the following selection criteria: farm located within Washington State and operated as a commercial dairy farm. According to the Dairy Farmers of Washington (2007; http://www. havemilk.com), there were 496 dairy farms and 238,000 milk cows in Washington. Sample size calculation was performed as described previously (Christensen and Gardner, 2000) with consideration of the herd-level sensitivity (0.95), expected disease prevalence $(8 \%$ or more), and expected test sensitivity (0.5). These farms represented 173,253 dairy cattle in Washington State. Dairy farms were selected across the 3 major dairy areas (western, central, and south-central) of the state, proportional to the total dairy farms in that region. Sixty-six farms were randomly selected alphabetically from a list of dairies, and contact was made through telephone and herd veterinarian to explain the project. Sixty farms were enrolled and 1 farm went out of business during the study, leaving us with 59 farms for study; 6 declined participation. Management-related information was collected via a standardized questionnaire and by on-site inspections (Table 1).

In Washington State, herd veterinarians regularly submit fecal samples to the Washington Disease Diagnostic Laboratory (WADDL, Pullman, WA) for suspected cases of salmonellosis. Information about historical cases of salmonellosis (within $3 \mathrm{yr}$ of the start of the current study) and isolates were obtained from WADDL.

\section{Sampling Plan}

Each farm was visited 7 times at intervals of 2 to 4 mo over a period of 15 to 21 mo to collect samples. All samplings occurred between August 2005 and December 2007. A total of 7,009 pooled fecal samples were collected from the participating herds. Each fecal pool consisted of approximately $5 \mathrm{~g}$ of feces randomly collected from 10 individual, undisturbed fresh fecal pats 
from the ground in the pen using sterile tongue depressors. An average of 16 fecal pools was collected per farm visit from different groups of cattle. These fecal samples were collected from lactating cows (3-9 pools), 2 to 3 dry cows ( $2-3$ pools), close-up dry cows $(2-3$ pools $)$, heifers (1-2 pools), cows in the maternity/hospital area (1-2 pools), and calves (1 pool). The number of fecal pools was adjusted according to the number of strings per group of animals. The more strings per group of target animals (e.g., lactating cows), the greater the number of fecal pools were collected. This sampling method was estimated to provide at least $95 \%$ probability of detecting a positive herd if the within-herd prevalence was $8 \%$ or more (Jordan, 2005). The sensitivity was likely to be higher than the computed number because more samples were collected from target populations (calves, lactating cows, maternity/hospital cows) reported to be at increased risk of infection (Hancock, 1996; Warnick et al., 2003a). A slurry sample of $50 \mathrm{~mL}$ from slurry pond was collected from each dairy farm.

\section{Salmonella Culture and Identification}

For isolation of Salmonella spp. from the feces, 12.5 $\mathrm{g}$ of each fecal sample was enriched in $112.5 \mathrm{~mL}$ of tetrathionate broth (Hardy Diagnostics, Santa Maria, $\mathrm{CA}$ ) and $112.5 \mathrm{~mL}$ of Rappaport-Vassiliadis broth (Hardy Diagnostics). The cultures were incubated for $48 \mathrm{~h}$ at $42^{\circ} \mathrm{C}$. Each enriched sample was plated onto xylose lysine tergitol-4 (XLT-4, Hardy Diagnostics) agar and MacConkey (Mac, Hardy Diagnostics) agar supplemented with ampicillin $(256 \mu \mathrm{g} / \mathrm{mL})$, chloramphenicol $(8 \mu \mathrm{g} / \mathrm{mL})$, and streptomycin $(32 \mu \mathrm{g} / \mathrm{mL}$; Sigma-Aldrich, Dallas, TX). The plates were incubated for $24 \mathrm{~h}$ at $37^{\circ} \mathrm{C}$. In this method, 2 XLT- 4 and 2 Mac plates per sample were used. All the Mac plates contained antibiotics as described above, whereas XLT-4 plates did not contain any antibiotics. For isolation of Salmonella spp. from the slurry, $25 \mathrm{~mL}$ of slurry sample was pre-enriched in $225 \mathrm{~mL}$ of buffered peptone water (BPW; Hardy Diagnostics) and incubated for $24 \mathrm{~h}$ at $37^{\circ} \mathrm{C}$. Pre-enrichment steps were followed by enrichment steps by transferring $1 \mathrm{~mL}$ of $\mathrm{BPW}$ to $9 \mathrm{~mL}$ of tetrathionate broth and $100 \mu \mathrm{L}$ of BPW to $10 \mathrm{~mL}$ of Rappaport-Vassiliadis broth and incubating for $48 \mathrm{~h}$ at $42^{\circ} \mathrm{C}$. The enriched sample was plated onto XLT- 4 and Mac agar plates and incubated for $24 \mathrm{~h}$ at $37^{\circ} \mathrm{C}$. For confirmation of suspected Salmonella, 3 colonies from XLT-4 and Mac plates were inoculated onto lysine iron agar slants and incubated for $24 \mathrm{~h}$ at $37^{\circ} \mathrm{C}$. Salmonella suspects from lysine iron agar were transferred to triple sugar iron agar slants and subsequently to urea agar slants and were incubated for 18 to $24 \mathrm{~h}$ at $37^{\circ} \mathrm{C}$. One isolate per sample was further screened with agglutina- tion tests for serogroup identification using commercial polyvalent A-I and Vi antisera (Difco Laboratory, Detroit, MI). Isolates were then banked in brain-heart infusion broth containing 25 to $30 \%$ buffered glycerol and stored at $-80^{\circ} \mathrm{C}$. One isolate per sample (except when different serogroups were detected for the same sample on 2 different culture media) was selected for further characterization by antimicrobial susceptibility testing. Isolates showing antimicrobial resistance to 2 or more antimicrobials belonging to distinct classes of antimicrobial agents were designated as MDR isolates. One MDR isolate (except for isolate with multiple serogroups) per sample per visit was serotyped at the National Veterinary Service Laboratory (Ames, IA).

\section{Antimicrobial Susceptibility Testing}

Antimicrobial susceptibility testing was performed using the Kirby-Bauer disk diffusion method (Bauer et al., 1966). Each isolate was classified as resistant or susceptible to each antimicrobial drug tested by the threshold zone size for resistance, as recommended by Clinical and Laboratory Standards Institute (formerly NCCLS) guidelines (NCCLS, 2003a,b), using the following antimicrobial drugs (BD Diagnostics, Sparks, MD): ampicillin $(10 \mu \mathrm{g})$, ceftazidime $(30 \mu \mathrm{g})$, chloramphenicol $(30 \mu \mathrm{g})$, gentamicin $(10 \mu \mathrm{g})$, amoxicillin-clavulanic acid $(20 / 10 \mu \mathrm{g})$, kanamycin $(30 \mu \mathrm{g})$, streptomycin (10 $\mu \mathrm{g})$, tetracycline $(30 \mu \mathrm{g})$, triple-sulfa (a combination of sulfadiazine, sulfamethazine, and sulfamerazine; 250 $\mu \mathrm{g})$, and trimethoprim-sulfamethoxazole (1.25/23.75 $\mu \mathrm{g})$. These antimicrobial agents are the most relevant to both human and veterinary medicine. All Salmonella isolates were screened for antimicrobial susceptibility phenotypes using 10 different antimicrobial agents. Isolates classified as being MDR were further examined by serotyping and pulsed-field gel electrophoresis (PFGE).

\section{PFGE}

All 411 MDR Salmonella isolates from fecal samples were analyzed by PFGE following $X b a$ I restriction digestion based on the PulseNet protocol for Salmonella using Salmonella Braenderup H9812 as a size standard (Hunter et al., 2005). The PFGE images were analyzed using BioNumerics v. 3.5 software (Applied Maths, Sint-Martens-Latem, Belgium). Independent strains were defined by PFGE profiles that differed in at least 2 bands with a position tolerance of $1.5 \%$.

\section{New MDR Salmonella Strain Introduction}

Isolates from the first farm sampling or from prestudy diagnostic samples submitted to WADDL during 
the previous 3 yr were considered pre-existing strains. For the purpose of this article, a strain found on the farm was considered a newly introduced strain (based on 2 or more PFGE band differences) if the strain was isolated at the second or later sampling visit and had not been observed on that farm in the first sampling visit or in diagnostic samples from suspected clinical cases for at least 3 or more years before the commencement of the study.

\section{Data Analysis}

Univariate analysis was performed to evaluate the unadjusted association between individual variables and the introduction of any new MDR Salmonella strains. Variables with $P$-values $<0.25$ were entered into multivariable models in a stepwise manner. This was a preselection of variables to enter into the multivariable model. Logistic regression analysis was used to evaluate the association between potential herd-level factors and the probability of whether any new MDR strain had been introduced during the study period. Negative binomial regression was used to test the same factors for association with the number of new MDR Salmonella strains introduced during the study period. The main effects as well as interaction terms were retained in the final multivariate model if they were significant at a $P$-value $<0.05$. The number of months during which a herd was sampled was forced in the model to examine its potential confounding effect. All analyses were performed with SAS v.9.1 software (SAS Institute Inc., Cary, NC) and Excel (Microsoft, Redmond, WA).

\section{RESULTS}

A total of 1,113 Salmonella spp. were isolated from 59 farms. One farm that had an incomplete data set (the farm went out of business) was excluded in this analysis. Of the 1,113 isolates, 385 were multidrugresistant. Multidrug-resistant Salmonella spp. were isolated from $66 \%(39 / 59)$ of dairy herds (Table 2). Forty-six percent $(27 / 59)$ of herds did not acquire any new MDR Salmonella strains, whereas the number of new MDR Salmonella strains acquired by the remaining 54\% (32/59) of herds ranged from 1 to 8 (Table $3)$. Seventeen herds were positive for a single newly acquired strain, whereas 2 of the 33 herds each acquired 8 MDR Salmonella strains.

Historical information on clinical Salmonella infection from participating herds (Table 4) indicated that 13 of 59 herds were diagnosed with clinical salmonellosis before the study based on Salmonella-positive clinical sample submissions to WADDL. Twenty-six MDR Salmonella enterica isolates were detected on clinical submission samples. Historical MDR Salmonella strains listed in Table 2 were not isolated in the current study. All 26 isolates were resistant to ampicillin, followed by 25 isolates resistant to triple-sulfa, streptomycin, and tetracycline, 16 isolates resistant to chloramphenicol, 14 isolates resistant to ceftazidime, 13 isolates resistant to kanamycin, 4 isolates resistant to trimethoprim-sulfadimethoxazole, and 2 isolates resistant to gentamicin. All isolates were resistant to at least 5 antimicrobials, and $5(19 \%)$ were resistant to 7 or more antimicrobials. Salmonella Typhimurium was the most $(12 / 26)$ commonly identified serovar followed by Salmonella Newport $(9 / 26)$.

Table 5 summarizes the distribution and PFGE profiles of newly introduced MDR Salmonella serovars isolated from commercial dairy herds enrolled in the study between January 2006 and December 2007. Of the 59 herds, new strains of serovar Typhimurium were acquired by 20 (34\%) herds, serovar Dublin by $9(15 \%)$ herds, serovar Newport by $5(8 \%)$ herds, and serovars Infantis, Montevideo, and Uganda by 3 herds each. Among the newly introduced strains of Salmonella, 13, 10, and 9 strains belonged to serovars Typhimurium, Newport, and Dublin, respectively. The strain designated T5 was the most frequently introduced strain of serovar Typhimurium isolated in several dairy herds. Other new strains include Hadar; Ohio; Oranienburg; I 4,12:Nonmotile; I Rough: 6,7:-; I Rough:6,8:-; I 9,12:Nonmotile; I Rough:9,12:-; I Rough:-; and I Rough:6,8:-. A high diversity of antimicrobial resistance was observed within serovars and PFGE subtypes.

Three variables were found to be significantly associated with new MDR Salmonella strain introduction in univariate analyses (Table 6): heifer off-farm raising, including contract heifer raising with commingling of cattle from other sources [unadjusted odds ratio (OR) $=6.6]$; salmonellosis diagnosed in the herd in the last 3 yr (unadjusted OR $=5.4$ ); and herd size in 100-animal increments $(\mathrm{OR}=1.015)$. These variables were also found to be significantly associated with the number of new MDR Salmonella strains introduced in participating herds (unadjusted $\mathrm{OR}=2.0,3.3$, and 1.02, respectively).

The multivariable logistic regression model showed that the practice of raising heifers off-farm in situations where the heifers were commingled with cattle from other sources [commingled heifers, adjusted OR $=8.9$, 95\% confidence interval (CI), 2.4-32.8], and increasing herd size in 100-animal increments (herd size, adjusted $\mathrm{OR}=1.04,95 \% \mathrm{CI}, 1.01-1.05)$ were significantly associated with MDR Salmonella strain introductions into dairies (Table 7). Multivariable negative binomial regression also showed that commingled heifers and increasing herd size were significantly associated with the 
Table 2. Salmonella spp. isolation from pooled fecal samples in commercial dairies in the northwestern United States

\begin{tabular}{|c|c|c|c|c|c|c|c|}
\hline Farm $^{1}$ & $\begin{array}{c}\text { Pooled } \\
\text { sample, } \mathrm{n}\end{array}$ & $\begin{array}{l}\text { Non-MDR }^{2} \\
\text { Salmonella }\end{array}$ & $\begin{array}{c}\text { MDR } \\
\text { Salmonella }\end{array}$ & Farm & $\begin{array}{c}\text { Pooled } \\
\text { sample, n }\end{array}$ & $\begin{array}{l}\text { Non-MDR } \\
\text { Salmonella }\end{array}$ & $\begin{array}{c}\text { MDR } \\
\text { Salmonella }\end{array}$ \\
\hline 1 & 158 & 6 & 0 & 32 & 131 & 5 & 9 \\
\hline 2 & 150 & 6 & 14 & 33 & 128 & 16 & 61 \\
\hline 3 & 147 & 2 & 4 & 35 & 132 & 1 & 3 \\
\hline 4 & 128 & 9 & 0 & 36 & 75 & 5 & 1 \\
\hline 5 & 161 & 3 & 2 & 37 & 115 & 19 & 0 \\
\hline 6 & 121 & 0 & 0 & 38 & 113 & 3 & 1 \\
\hline 7 & 109 & 0 & 2 & 39 & 129 & 3 & 20 \\
\hline 8 & 110 & 14 & 1 & 40 & 93 & 1 & 0 \\
\hline 9 & 100 & 0 & 1 & 41 & 85 & 2 & 0 \\
\hline 10 & 100 & 1 & 16 & 42 & 117 & 22 & 2 \\
\hline 11 & 120 & 8 & 0 & 44 & 120 & 2 & 3 \\
\hline 12 & 113 & 0 & 80 & 45 & 127 & 18 & 7 \\
\hline 13 & 99 & 0 & 1 & 46 & 124 & 14 & 24 \\
\hline 14 & 115 & 0 & 0 & 47 & 135 & 5 & 0 \\
\hline 15 & 117 & 4 & 0 & 48 & 123 & 3 & 3 \\
\hline 16 & 74 & 0 & 0 & 49 & 121 & 19 & 6 \\
\hline 17 & 123 & 54 & 0 & 50 & 75 & 0 & 0 \\
\hline 18 & 131 & 28 & 1 & 51 & 126 & 3 & 23 \\
\hline 19 & 180 & 1 & 1 & 52 & 111 & 25 & 1 \\
\hline 20 & 133 & 17 & 0 & 53 & 124 & 37 & 15 \\
\hline 21 & 116 & 26 & 0 & 54 & 120 & 7 & 0 \\
\hline 22 & 126 & 52 & 2 & 55 & 113 & 0 & 2 \\
\hline 23 & 189 & 51 & 2 & 56 & 110 & 0 & 0 \\
\hline 25 & 124 & 43 & 1 & 57 & 117 & 60 & 6 \\
\hline 26 & 119 & 2 & 0 & 58 & 94 & 1 & 4 \\
\hline 27 & 85 & 0 & 0 & 59 & 106 & 22 & 11 \\
\hline 28 & 81 & 0 & 9 & 60 & 126 & 6 & 13 \\
\hline 29 & 131 & 14 & 8 & 61 & 129 & 2 & 20 \\
\hline 30 & 107 & 2 & 0 & 62 & 108 & 30 & 1 \\
\hline 31 & 115 & 56 & 2 & & & & \\
\hline
\end{tabular}

${ }^{1}$ Two feed mills numbered as farm 23 and 43. Sixty farms and 2 feed mills were numbered consecutively while enrolling farms and feed mills. However, feed mills are not included in this table. Farm 43 went out of business and its data were not included in the analysis.

${ }^{2} \mathrm{MDR}=$ multidrug resistant

number of new MDR Salmonella strain introductions [adjusted relative risk $(\mathbf{R R})=2.3,95 \%$ CI, 1.1-4.7 and adjusted $\mathrm{RR}=1.02,95 \% \mathrm{CI}, 1.01-1.03$, respectively; Table 8]. In addition, clinical salmonellosis diagnosed in the herd in the $3 \mathrm{yr}$ before the start of the study was also significantly associated with the number of new MDR Salmonella strain introductions (adjusted RR = $2.5,95 \% \mathrm{CI}, 1.3-5.0)$. No interaction terms were found to be significant.

\section{DISCUSSION}

In the present study, we investigated the role of animal movement in the interherd transmission of MDR Salmonella spp. because the transport of Salmonellainfected animals onto farms has been recognized as a primary route of Salmonella introduction on farms (Evans, 1996; Zansky et al., 2002; Vanselow et al., 2007). Our data indicate that $49 \%$ of the dairy farms raised heifers off-farm in ranches where they commingled with cattle from several sources. A recent study in the northeastern United States reported a similarly high percentage of dairy farms that sent calves to a custom raiser (Fulwider et al., 2008).

We found that $27(46 \%)$ of the herds did not acquire any new MDR Salmonella strains, whereas 32 (54\%) of herds acquired one or more new MDR Salmonella strains during the study period. The presence of heifers raised off-farm on ranches where heifers commingle with cattle from several sources was found to be a significant risk factor for introduction of new MDR

Table 3. Introduction of new multidrug-resistant (MDR) Salmonella strains into 59 commercial dairies in the northwestern United States

\begin{tabular}{lc}
\hline $\begin{array}{l}\text { New MDR Salmonella } \\
\text { strains introduced, } \mathrm{n}\end{array}$ & Farms, $\mathrm{n}(\%)$ \\
\hline 0 & $27(46)$ \\
1 & $17(29)$ \\
2 & $5(8)$ \\
3 & $7(12)$ \\
6 & $1(2)$ \\
8 & $2(3)$ \\
\hline
\end{tabular}


Table 4. Historical information on previous clinical multidrug-resistant Salmonella spp. isolates from the dairy farms enrolled in the study

\begin{tabular}{|c|c|c|c|c|}
\hline Farm & Serovar & PFGE type ${ }^{1}$ & $\begin{array}{l}\text { Antimicrobial } \\
\text { resistance type }\end{array}$ & Isolates, $\mathrm{n}$ \\
\hline 1 & Typhimurium & TYP004 & ACSTSu & 1 \\
\hline \multirow[t]{2}{*}{2} & Newport & NEW005 & ACSTSuCaz & 1 \\
\hline & Typhimurium & wTYP041 & ACKSxtSTSu & 1 \\
\hline 8 & Newport & NEW013 & ASTSuCaz & 2 \\
\hline 14 & Heidelberg & wHEI006 & ACGKSTSuCaz & 1 \\
\hline 18 & Newport & NEW005 & ACSTSuCaz & 1 \\
\hline 20 & Typhimurium & TYP035 & AKSTSu & 1 \\
\hline \multirow[t]{3}{*}{32} & Dublin & wDUB022 & ACGKSxtSTSuCaz & 1 \\
\hline & Typhimurium & TYP021 & AKSTSu & 3 \\
\hline & & wTYP115 & AKSTSu & 1 \\
\hline \multirow[t]{2}{*}{33} & Bardo & NEW005 & ACSTSuCaz & 1 \\
\hline & Newport & NEW005 & ACSTSuCaz & 3 \\
\hline \multirow[t]{4}{*}{37} & Meleagridis & wMEL003 & AAmcCaz & 1 \\
\hline & Newport & NEW005 & ACSTSuCaz & 1 \\
\hline & & & ACSTSuCaz & 1 \\
\hline & Typhimurium & TYP035 & AKSTSu & 1 \\
\hline 55 & Typhimurium & TYP018 & ACKSxtSTSu & 1 \\
\hline \multirow[t]{3}{*}{60} & 9,12 :Nonmotile & w9_12_N004 & ACKSTSu & 1 \\
\hline & Typhimurium & TYP035 & ACKSxtSTSuCaz & 1 \\
\hline & & w4_12_001 & AKSTSu & 1 \\
\hline 62 & Typhimurium & TYP004 & ACSTSu & 1 \\
\hline
\end{tabular}

${ }^{1}$ Pulsed-field gel electrophoresis type as designated by Washington Department of Public Health with the exception of types starting with the letter w, which indicates a new PFGE type designated at Washington State University.

${ }^{2} \mathrm{~A}=$ ampicillin; $\mathrm{C}=$ chloramphenicol; $\mathrm{G}=$ gentamicin; $\mathrm{K}=$ kanamycin; $\mathrm{S}=$ streptomycin; $\mathrm{Su}=$ triple sulfa; $\mathrm{T}$ $=$ tetracycline $; \mathrm{Caz}=$ ceftazidime; $\mathrm{Amc}=$ amoxicillin-clavulanic acid; Sxt $=$ trimethoprim-sulfamethoxazole.

Salmonella strains into commercial dairy herds. This finding indicates that off-farm heifer raising operations where calves commingled with cattle from other sources was significantly associated with an increased risk of negative dairy herds becoming positive for Salmonella. The results of this study corroborate a finding of a previous study (Hegde et al., 2005), in which the authors reported that the heifer-raising operation could serve as a clearinghouse for Salmonella spp. A recent study, however, reported that the risk of Salmonella transmission from the heifer feedlot back to the dairy was low (Edrington et al., 2008). The latter study, however, used only a limited number of dairy herds and no statistical analysis was performed.

Previous studies reported that purchase of cattle from other sources presents important risks of Salmonella transmission between herds (Wray et al., 1990; Evans and Davies, 1996; Zansky et al., 2002). The present study failed to find a significant effect of cattle purchases (cow, bulls, calves, and heifers) on introduction of new MDR Salmonella strains into commercial dairy herds. A recent study found that introduction of new cattle was not associated with Salmonella status dairy herds (Huston et al., 2002). It is not known why the present study did not find cattle purchase as a risk factor for interherd transmission of Salmonella; however, it is possible that the high rate of off-farm heifer raising (nearly $50 \%$ of the farms in the present study raised heifers off-farm, where they commingled with cattle from other sources, or replaced stock through contract heifer raising) mitigated the effects of cattle purchases in the present study. As a farm introduced more heifers as replacement stock through contract heifer-raising, they purchased fewer heifers directly from other farms.

Farms with a history of clinical salmonellosis were at increased risk of acquiring new Salmonella enterica strains. Although a previous study identified a significant association between recent clinical salmonellosis and detection of Salmonella in fecal samples from the same herd for up to 8 mo (Warnick et al., 2001), we did not find the same serovar in herds that had a history of clinical salmonellosis. It is unclear why background strains of Salmonella spp. did not persist in the present study herds, but this may be due to intermittent shedding patterns of Salmonella in cattle, environmental conditions, and other unknown factors. The discrepancy between our result and that of the Warnick et al. (2001) study could be related to the observations that clinical salmonellosis occurred in some of the participating herds in the present study more than a year before the start of the study, and herds with clinical salmonellosis were likely managed differently than noninfected herds. Given that the association was still significant after adjustment for other variables, this finding suggests 
Table 5. Pulsed field gel electrophoresis (PFGE) profiles and antimicrobial resistance phenotypes of newly introduced multidrug-resistant Salmonella strains isolated from the study herds

\begin{tabular}{|c|c|c|c|c|c|}
\hline $\begin{array}{l}\text { Strain type } \\
\text { designation }\end{array}$ & Serovar & PFGE type $^{1}$ & $\begin{array}{l}\text { Antimicrobial } \\
\text { resistance type }\end{array}$ & $\begin{array}{l}\text { Farms, } \\
\mathrm{n}\end{array}$ & Farm ID \\
\hline A & I 4,12:Nonmotile & wTYP014 & AKTSu & 1 & 57 \\
\hline $\mathrm{B}$ & I Rough: $6,7: \mathrm{-}^{3}$ & wNEW012 & $\mathrm{AAmc}$ & 1 & 60 \\
\hline $\mathrm{C}$ & I Rough:6,8:- ${ }^{3}$ & wNEW035 & AAmc & 1 & 62 \\
\hline $\mathrm{CC}$ & I 9,12:Nonmotile & w9_12_N003 & ACGKSTAmcSuCaz & 1 & 23 \\
\hline $\mathrm{E}$ & I Rough: $9,12:{ }^{3}$ & wD1_001 & ACSxtSTAmcSu & 1 & 52 \\
\hline $\mathrm{F}$ & I Rough: ${ }^{3}$ & wINF001 & ACKSTAmcSuCaz & 1 & 51 \\
\hline \multirow[t]{3}{*}{ D1 } & \multirow[t]{3}{*}{ Dublin } & w9,12:N002 & ACSTAmcSuCaz & 1 & 36 \\
\hline & & wDUB002 & ACSTSu & 1 & 3 \\
\hline & & wDUB002 & AKAmcSuCaz & 1 & 51 \\
\hline D2 & Dublin & wDUB003 & ACGKTAmcSuCaz & 1 & 32 \\
\hline D3 & Dublin & wDUB004 & ACGKTAmcSuCaz & 2 & 29,44 \\
\hline D4 & Dublin & wDUB007 & ACGKSTAmcSuCaz & 1 & 9 \\
\hline D5 & Dublin & wDUB008 & $\mathrm{AAmcSuCaz}$ & 1 & 3 \\
\hline D6 & Dublin & wDUB009 & ACSTSu & 1 & 51 \\
\hline D7 & Dublin & wDUB012 & ACKTAmcSuCaz & 1 & 32 \\
\hline D8 & Dublin & wDUB016 & ACGKSTAmcSuCaz & 1 & 7 \\
\hline G1 & Meleagridis & wMEL001 & AAmcCaz & 1 & 2 \\
\hline H1 & Hadar & wHAD001 & ST & 1 & 8 \\
\hline $\mathrm{H} 2$ & Hadar & wHAD004 & ST & 1 & 10 \\
\hline \multirow[t]{2}{*}{ I1 } & \multirow[t]{2}{*}{ Infantis } & \multirow[t]{2}{*}{ wINF001 } & ACSTAmcSuCaz & 2 & 32,33 \\
\hline & & & ACSTAmcSulCaz & 1 & 39 \\
\hline \multirow[t]{2}{*}{ N1 } & \multirow[t]{2}{*}{ Newport } & \multirow[t]{2}{*}{ NEW005 } & ACSTAmcSu & 1 & 35 \\
\hline & & & ACSTAmcSuCaz & 1 & 60 \\
\hline $\mathrm{N} 2$ & Newport & NEW046 & ASTAmcSuCaz & 2 & 10,18 \\
\hline N3 & Newport & NEW076 & ASTAmcSuCaz & 1 & 10 \\
\hline N4 & Newport & wNEW005 & ACSTAmcSuCaz & 1 & 12 \\
\hline N5 & Newport & wNEW010 & ACSTAmcSuCaz & 1 & 12 \\
\hline N6 & Newport & wNEW013 & ACSTAmcSuCaz & 1 & 12 \\
\hline N7 & Newport & wNEW015 & ACSTAmcSuCaz & 1 & 12 \\
\hline N8 & Newport & wNEW016 & ACSTAmcSuCaz & 1 & 12 \\
\hline N9 & Newport & wNEW018 & ACSTAmcSuCaz & 1 & 12 \\
\hline N10 & Newport & wNEW036 & ACSTAmcSuCaz & 1 & 12 \\
\hline $\mathrm{O}$ & Ohio & wOHI001 & $\mathrm{TSu}$ & 1 & 33 \\
\hline $\mathrm{R}$ & Oranienburg & wORA001 & AAmcCaz & 1 & 25 \\
\hline $\mathrm{T} 1$ & Typhimurium & TYP004 & ACSTSu & 1 & 46 \\
\hline $\mathrm{T} 2$ & Typhimurium & TYP012 & ASSu & 1 & 33 \\
\hline T3 & Typhimurium & TYP016 & AKSTSu & 1 & 53 \\
\hline $\mathrm{T} 4$ & Typhimurium & TYP139 & AKSTSu & 1 & 33 \\
\hline \multirow[t]{5}{*}{ T5 } & Typhimurium & TYP035/187 & AKSTAmcSuCaz & 7 & $2,3,5,12,39,42,57$ \\
\hline & Typhimurium & TYP035/187 & AKSTAmcSuCaz & 1 & 48 \\
\hline & Typhimurium & TYP035/187 & AKSTSu & 3 & $23,29,49$ \\
\hline & Typhimurium & TYP035/187 & AKSTSuCaz & 1 & 45 \\
\hline & Typhimurium & TYP035/187 & AKSxtSTAmcSuCaz & 1 & 44 \\
\hline T6 & Typhimurium & TYP139 & AKSTAmcSuCaz & 1 & 51 \\
\hline $\mathrm{T} 7$ & Typhimurium & wTYP002 & ACSTSu & 1 & 46 \\
\hline T8 & Typhimurium & wTYP013 & AKT & 1 & 33 \\
\hline T9 & Typhimurium & wTYP013a & KSTSu & 1 & 31 \\
\hline T10 & Typhimurium & wTYP062 & AKSTSu & 1 & 60 \\
\hline T11 & Typhimurium & wTYP093 & AKSTAmcSuCaz & 1 & 51 \\
\hline $\mathrm{T} 12$ & Typhimurium & wTYP108 & ACKSTAmcSuCaz & 1 & 51 \\
\hline $\mathrm{T} 13$ & Typhimurium & wTYP113 & AKSTAmcSuCaz & 1 & 51 \\
\hline $\mathrm{T} 14$ & Typhimurium & wTYP114 & AKSTAmcSuCaz & 1 & 51 \\
\hline U1 & Uganda & wUGA001 & CKSxtSTSu & 2 & 19,28 \\
\hline $\mathrm{U} 2$ & Uganda & wUGA010 & CKSxtSTNalSu & 1 & 39 \\
\hline V1 & Montevideo & wMON006 & ACSTAmcSuCaz & 1 & 29 \\
\hline V2 & Montevideo & wMON007 & ACSxtSTAmcSu & 1 & 31 \\
\hline V3 & Montevideo & wMON022 & ACGKSTAmcSuCaz & 1 & 57 \\
\hline
\end{tabular}

${ }^{1}$ PFGE type as designated by Washington Department of Public Health with the exception of types starting with the letter $\mathrm{w}$, which indicates a new PFGE type designated at Washington State University.

${ }^{2} \mathrm{~A}=$ ampicillin; $\mathrm{C}=$ chloramphenicol; $\mathrm{G}=$ gentamicin; $\mathrm{K}=$ kanamycin; $\mathrm{S}=$ streptomycin; $\mathrm{Su}=$ triple sulfa; $\mathrm{T}$ $=$ tetracycline $; \mathrm{Caz}=$ ceftazidime $; \mathrm{Amc}=$ amoxicillin-clavulanic acid; Sxt $=$ trimethoprim-sulfamethoxazole.

${ }^{3}$ Popoff (2001). 
Table 6. Univariate analyses of herd-level factors associated with introduction of one or more new multidrug-resistant (MDR) Salmonella strains into dairy herds in the northwestern United States

\begin{tabular}{|c|c|c|c|c|c|}
\hline \multirow[b]{2}{*}{ Variable } & \multirow[b]{2}{*}{ Level } & \multicolumn{2}{|c|}{$\begin{array}{c}\text { Any new MDR Salmonella } \\
\text { introduction }\end{array}$} & \multicolumn{2}{|c|}{$\begin{array}{l}\text { Number of new MDR } \\
\text { Salmonella introductions }\end{array}$} \\
\hline & & $P$-value & Odds ratio & $P$-value & Relative risk \\
\hline \multirow[t]{2}{*}{ Any cows purchased } & Yes & 0.86 & 0.88 & 0.65 & 1.3 \\
\hline & No & & 1 & & 1 \\
\hline \multirow[t]{2}{*}{ Any bulls purchased } & Yes & 0.66 & 1.28 & 0.45 & 0.7 \\
\hline & No & & 1 & & 1 \\
\hline \multirow{2}{*}{ Any heifers purchased } & Yes & 0.1 & 0.36 & 0.99 & 1 \\
\hline & No & & 1 & & 1 \\
\hline \multirow{2}{*}{ Any cattle purchased } & Yes & 0.38 & 0.63 & 0.31 & 0.69 \\
\hline & No & & 1 & & 1 \\
\hline Herd size & Per 100 animals & 0.24 & 1 & 0.02 & 1 \\
\hline Number of cows purchased ${ }^{1}$ & Number & 0.54 & 0.92 & 0.52 & 1 \\
\hline Number of bulls purchased ${ }^{1}$ & Number & 0.07 & 0.88 & 0.46 & 0.99 \\
\hline \multirow[t]{2}{*}{ History of clinical salmonellosis } & Yes & 0.01 & 5.4 & $<0.01$ & 3.3 \\
\hline & No & & 1 & & 1 \\
\hline \multirow[t]{2}{*}{ Heifers commingled $^{2}$} & Yes & $<0.01$ & 6.6 & 0.05 & 2 \\
\hline & No & & 1 & & 1 \\
\hline \multirow[t]{2}{*}{ Heifers and cows in the same close-up pen } & Yes & 0.54 & 0.7 & 0.57 & 1.2 \\
\hline & No & & 1 & & 1 \\
\hline
\end{tabular}

${ }^{1}$ Numbers in $\log _{10}$ scale.

${ }^{2}$ Off-farm raised heifers including contract-raised heifers commingled with cattle from other sources.

the existence of important risk factors for the introduction of new strains that were not found in the present study. Previous studies suggest that recent antimicrobial treatment can increase the probability of isolating Salmonella in calves, heifers, and cows (Warnick et al., 2003b; Berge et al., 2006). It is possible that antimicrobial use at the farm level increases the susceptibility of dairy herds to acquire new strains.

Culture-dependent isolation of Salmonella spp. is naturally less than $100 \%$ sensitive. However, methods such as pooling of samples, targeted sampling, and sample pre-enrichment were used to improve the recovery of damaged cells and subsequent isolation rates. Initial assessment of Salmonella strains present in the dairy farms was based on more intensive sampling around dairy farms. Certain sample types were targeted (e.g., pooled sampling, milk filters, slurry) that increase the chances of determining herd-wide status. Cattle sampling was divided between different groups of cattle on the farm (e.g., heifers, lactating, dry), as Salmonella and MDR Salmonella prevalences have been demonstrated to vary significantly between these groups (Warnick et al., 2003a; Cobbold et al., 2006). It is possible that a pre-existing strain was missed, but the chance of this occurring was minimized through the sampling and microbiological methods employed.

The results of our study indicate that increased herd size was significantly and positively associated with

Table 7. Multivariable logistic regression model for examination of the management variable as a risk factor for the introduction of multidrugresistant Salmonella strains into dairy herds

$95 \%$ confidence interval $^{1}$

\begin{tabular}{llccccc} 
& Coding & Odds ratio & $\chi^{2}$ & Lower bound & Upper bound & $P$-value \\
\cline { 5 - 6 } Variable & Yes & 8.9 & 10.7 & 2.4 & 32.8 & 0.001 \\
Herd size & No & 1 & & 1.01 & 1.05 & 0.031 \\
\hline
\end{tabular}

${ }^{1}$ Maximum likelihood approximation

${ }^{2}$ Off-farm raised heifers including contract-raised heifers commingled with cattle from other sources. 
Table 8. Multivariable negative binomial regression model for examination of management variables as a risk factor for the introduction of multiple new multidrug-resistant Salmonella strains into dairy herds

\begin{tabular}{|c|c|c|c|c|c|c|}
\hline \multirow[b]{2}{*}{ Variable } & \multirow[b]{2}{*}{ Coding } & \multirow[b]{2}{*}{ Relative risk } & \multirow[b]{2}{*}{$\chi^{2}$} & \multicolumn{2}{|c|}{$95 \%$ confidence interval $^{1}$} & \multirow[b]{2}{*}{$P$-value } \\
\hline & & & & Lower bound & Upper bound & \\
\hline Off-farm commingled ${ }^{2}$ & $\begin{array}{l}\text { Yes } \\
\text { No }\end{array}$ & $\begin{array}{l}2.3 \\
1\end{array}$ & 5.5 & 1.1 & 4.7 & $\begin{array}{l}0.019 \\
\text { Reference }\end{array}$ \\
\hline Salmonellosis in last $3 \mathrm{yr}^{3}$ & $\begin{array}{l}\text { Yes } \\
\text { No }\end{array}$ & $\begin{array}{l}2.5 \\
1\end{array}$ & 6.8 & 1.3 & 5 & $\begin{array}{l}0.009 \\
\text { Reference }\end{array}$ \\
\hline Herd size & Per 100 increase & 1.02 & 9.3 & 1.01 & 1.03 & 0.002 \\
\hline
\end{tabular}

${ }^{1}$ Maximum likelihood approximation.

${ }^{2}$ Off-farm raised heifers including contract-raised heifers commingled with cattle from other sources.

${ }^{3}$ Clinical salmonellosis diagnosed in the 3 -yr period preceding the study period.

increased risk of introduction of new MDR Salmonella strains and with increased numbers of new MDR Salmonella introductions. This finding corroborates that of another study, which found that increases in herd size and the number of cattle purchased from testpositive herds in the previous year-quarter were significantly and positively associated with an increased risk of negative herds becoming positive for Salmonella (Nielsen et al., 2007). Several previous studies also found an association between herd size and Salmonella prevalence, which might be affected by the Salmonella introduction rate (Kabagambe et al., 2000; Huston et al., 2002; Warnick et al., 2003b).

In conclusion, the findings of the present study strongly implicate off-farm rearing of heifers in the transmission of MDR Salmonella strains between farms. Other factors, including increased herd size and a history of clinical salmonellosis, were also associated with the introduction of MDR Salmonella into dairy herds. For future studies, other important risk factors associated with interherd transmission of Salmonella should be investigated. Studies are needed to clarify whether and how off-farm rearing of heifers can be done without increasing the risk of Salmonella introduction.

\section{ACKNOWLEDGMENTS}

This project was supported in part by the National Institute of Health, Department of Health and Human Services under the contract number NO1-AI-30055 and by the Agricultural Animal Health Program, College of Veterinary Medicine, Washington State University. The skillful technical assistance of Katherine Kaya Baker [Field Disease Investigation Unit (FDIU), College of Veterinary Medicine, Washington State University] is gratefully acknowledged. We also thank Lindsay Tippett, Lisa Jones, and other staff of the FDIU for their technical assistance.

\section{REFERENCES}

Bauer, A. W., W. M. Kirby, J. C. Cherris, and M. Turck. 1966. Antibiotic susceptibility testing by a standardized single disk method. Am. J. Clin. Pathol. 45:493-496.

Berge, A. C., D. A. Moore, and W. M. Sischo. 2006. Prevalence and antimicrobial resistance patterns of Salmonella enterica in preweaned calves from dairies and calf ranches. Am. J. Vet. Res. 67:1580-1588.

Besser, T. E., C. C. Gay, J. M. Gay, D. D. Hancock, D. Rice, L. C. Pritchett, and E. D. Erickson. 1997. Salmonellosis associated with $S$. Typhimurium DT104 in the USA. Vet. Rec. 140:75.

Besser, T. E., M. Goldoft, L. C. Pritchett, R. Khakhria, D. D. Hancock, D. H. Rice, J. M. Gay, W. Johnson, and C. C. Gay. 2000. Multiresistant Salmonella Typhimurium DT104 infections of humans and domestic animals in the Pacific Northwest of the United States. Epidemiol. Infect. 124:193-200.

Boqvist, S., and I. Vågsholm. 2005. Risk factors for hazard of release from Salmonella-control restriction on Swedish cattle farms from 1993 to 2002. Prev. Vet. Med. 71:35-44.

Butaye, P., G. B. Michael, S. Schwarz, T. J. Barrett, A. Brisabois, and D. G. White. 2006. The clonal spread of multidrug-resistant nontyphi Salmonella serotypes. Microbes Infect. 8:1891-1897.

Calvert, N., W. C. Stewart, and W. J. Reilly. 1998. Salmonella Typhimurium DT104 infection in people and animals in Scotland: A collaborative epidemiological study 1993-96. Vet. Rec. 143:351354.

CDC. 2006. Multistate outbreak of Salmonella Typhimurium infections associated with eating ground beef-United States, 2004. MMWR Morb. Mortal. Wkly. Rep. 55:180-182.

Christensen, J., and I. Gardner. 2000. Herd level interpretation of test results for epidemiologic studies of animal disease. Prev. Vet. Med. 45:83-106.

Cobbold, R. N., D. H. Rice, M. A. Davis, T. E. Besser, and D. D. Hancock. 2006. Long-term persistence of multi-drug-resistant Salmonella enterica serovar Newport in two dairy herds. J. Am. Vet. Med. Assoc. 228:585-591.

Dairy Farmers of Washington. 2007. Facts About the Washington Dairy Industry. http://www.havemilk.com/article.asp?id=2142 Accessed Nov. 20, 2008.

Davis, M. A., T. E. Besser, K. Eckmann, K. Macdonald, D. Green, D. D. Hancock, K. N. Baker, L. D. Warnick, Y. Soyer, M. Wiedmann, and D. R. Call. 2007. Multidrug-resistant Salmonella Typhimurium, Pacific Northwest, United States. Emerg. Infect. Dis. 13:1583-1586.

Davis, M. A., D. D. Hancock, T. E. Besser, D. H. Rice, J. M. Gay, C. Gay, L. Gearhart, and R. DiGiacomo. 1999. Changes in antimicrobial resistance among Salmonella enterica serovar Typhimurium isolates from humans and cattle in the Northwestern United States, 1982-1997. Emerg. Infect. Dis. 5:802-806. 
Edrington, T. S., T. R. Callaway, R. C. Anderson, and D. J. Nisbet. 2008. Prevalence of multidrug-resistant Salmonella on commercial dairies utilizing a single heifer raising facility. J. Food Prot. 71:27-34.

ERS/USDA. 2001. ERS estimates foodborne disease costs at $\$ 6.9$ billion per year. http://www.ers.usda.gov/Emphases/SafeFood Accessed Nov. 22, 2008.

Evans, S., and R. Davies. 1996. Case control study of multipleresistant Salmonella Typhimurium DT104 infection of cattle in Great Britain. Vet. Rec. 139:557-558.

Evans, S. J. 1996. A case control study of multiple resistant Salmonella Typhimurium DT 104 infection of cattle in Great Britain. Cattle Pract. 4:259-266.

Fey, P. D., T. J. Safranek, M. E. Rupp, E. F. Dunne, E. Ribot, P. C. Iwen, P. A. Bradford, F. J. Angulo, and S. H. Hinrichs. 2000 Ceftriaxone-resistant Salmonella infection acquired by a child from cattle. N. Engl. J. Med. 342:1242-1249.

Fulwider, W. K., T. Grandin, B. E. Rollin, T. E. Engle, N. L. Dalsted, and W. D. Lamm. 2008. Survey of dairy management practices on one hundred thirteen north central and northeastern United States dairies. J. Dairy Sci. 91:1686-1692.

Hancock, D. 1996. Strategic laboratory use: How to use hypothesisbased laboratory testing. Pages 118-125 in Proc. 28th Annu. Mtg. Am. Assoc. Bovine Pract.

Hancock, D., T. E. Besser, J. M. Gay, D. Rice, M. Davis, and C. Gay. 2000. The global epidemiology of multiresistant Salmonella enterica serovar Typhimurium DT104. Pages 217-243 in Emerging Diseases of Animals. C. Brown and C. A. Bolin, ed. ASM Press, Washington, DC.

Handeland, K., T. Refsum, B. S. Johansen, G. Holstad, G. Knutsen, I. Solberg, J. Schulze, and G. Kapperud. 2002. Prevalence of Salmonella Typhimurium in Norwegian hedgehog populations associated with two human disease outbreaks. Epidemiol. Infect. 128:523-527.

Hegde, N. V., M. L. Cook, D. R. Wolfgang, B. C. Love, C. C. Maddox, and B. M. Jayarao. 2005. Dissemination of Salmonella enterica subsp. enterica serovar Typhimurium var. Copenhagen clonal types through a contract heifer-raising operation. J. Clin. Microbiol. 43:4208-4211.

Hendriksen, S. W. M., K. Orsel, J. A. Wagenaar, A. Miko, and E. van Duijkeren. 2004. Animal-to-Human Transmission of Salmonella Typhimurium DT104 A Variant. Emerg. Infect. Dis. 10:22252227.

Hunter, S. B., P. Vauterin, M. A. Lambert-Fair, M. S. Van Duyne, K. Kubota, L. Graves, D. Wrigley, T. Barrett, and E. Ribot. 2005. Establishment of a universal size standard strain for use with the PulseNet standardized pulsed-field gel electrophoresis protocols: Converting the national databases to the new size standard. J. Clin. Microbiol. 43:1045-1050.

Huston, C. L., T. E. Wittum, B. C. Love, and J. E. Keen. 2002. Prevalence of fecal shedding of Salmonella spp. in dairy herds. J. Am. Vet. Med. Assoc. 220:645-649.

Jordan, D. 2005. Simulating the sensitivity of pooled-sample herd tests for fecal Salmonella in cattle. Prev. Vet. Med. 70:59-73.

Kabagambe, E. K., S. J. Wells, L. P. Garber, M. D. Salman, B. Wagner, and P. J. Fedorka-Cray. 2000. Risk factors for fecal shedding of Salmonella in 91 US dairy herds in 1996. Prev. Vet. Med. 43:177-194

Mazurek, J., E. Salehi, D. Propes, J. Holt, T. Bannerman, L. M. Nicholson, M. Bundesen, R. Duffy, and R. L. Moolenaar. 2004. A multistate outbreak of Salmonella enterica serotype Typhimurium infection linked to raw milk consumption-Ohio, 2003. J. Food Prot. 67:2165-2170.

Mead, P. S., L. Slutsker, V. Dietz, L. F. McCaig, J. S. Bresee, C. Shapiro, P. M. Griffin, and R. V. Tauxe. 1999. Food-related illness and death in the United States. Emerg. Infect. Dis. 5:607-625.

NCCLS. 2003a. National Committee for Clinical Laboratory Standards Approved Standard M2-A8. Performance Standards for Antimicrobial Disk Susceptibility Tests. 8th ed. NCCLS, Wayne, PA.
NCCLS. 2003b. National Committee for Clinical Laboratory Standards, M100-S13(M2). Disk Diffusion Supplemental Tables. NCCLS, Wayne, PA.

Nielsen, L. R., L. D. Warnick, and M. Greiner. 2007. Risk factors for changing test classification in the Danish surveillance program for Salmonella in dairy herds. J. Dairy Sci. 90:2815-2825.

Popoff, M. Y., J. Bockemühl, F. W. Brenner, and L. L. Gheesling. 2001. Supplement 2000 (no. 44) to the Kauffmann-White scheme. Res Microbiol. Dec.152:907-909.

Rice, D. H., D. D. Hancock, P. M. Roozen, M. H. Szymanski, B. C. Scheenstra, K. M. Cady, T. E. Besser, and P. A. Chudek. 2003. Household contamination with Salmonella enterica. Emerg. Infect. Dis. 9:120-122.

Ruiz, M., J. C. Rodriguez, I. Escribano, and G. Royo. 2004. Available options in the management of non-typhi Salmonella . Expert Opin. Pharmacother. 5:1737-1743.

Søbstad, Ø., J. Blinkenberg, E. Bergesen, A. Digranes, I. Tveit, E. Heir, G. Kapperud, T. Stavnes, V. Hasseltvedt, and B. G. Iversen. 2000. Transmission of salmonellosis through hedgehogs in Norway. Eurosurveillance Weekly 4:1.

Travers, K., and M. Barza. 2002. Morbidity of infections caused by antimicrobial-resistant bacteria. Clin. Infect. Dis. 34(Suppl. 3):S131-S134

USDA. 2007. Off-site heifer raising on U.S. dairy operations, 2007. http://www.aphis.usda.gov/vs/ceah/ncahs/nahms/dairy/ Accessed Nov. 2007

Van Kessel, J. S., J. S. Karns, D. R. Wolfgang, E. Hovingh, and Y. H. Schukken. 2007. Longitudinal study of a clonal, subclinical outbreak of Salmonella enterica subsp. enterica serovar Cerro in a U.S. dairy herd. Foodborne Pathog. Dis. 4:449-461.

Vanselow, B. A., M. A. Hornitzky, K. H. Walker, G. J. Eamens, G D. Bailey, P. A. Gill, K. Coates, B. Corney, J. P. Cronin, and S. Renilson. 2007. Salmonella and on-farm risk factors in healthy slaughter-age cattle and sheep in eastern Australia. Aust. Vet. J. $85: 498-502$.

Varma, J. K., K. Mølbak, T. J. Barrett, J. L. Beebe, T. F. Jones, T. Rabatsky-Ehr, K. E. Smith, D. J. Vugia, H. G. Chang, and F. J. Angulo. 2005. Antimicrobial-resistant nontyphoidal Salmonella is associated with excess bloodstream infections and hospitalizations. J. Infect. Dis. 191:554-561.

Wall, P. G., D. Morgan, K. Lamden, M. Griffin, E. J. Threlfall, L. R. Ward, and B. Rowe. 1995. Transmission of multi-resistant Salmonella Typhimurium from cattle to man. Vet. Rec. 136:591592.

Wall, P. G. D. Morgan, K. Lamden, M. Ryan, M. Griffin, E. J. Threlfall, L. R. Ward, and B. Rowe. 1994. A case control study of infection with an epidemic strain of multiresistant Salmonella Typhimurium DT104 in England and Wales. Commun. Dis. Rep. 4:R130-R135.

Warnick, L. D., L. M. Crofton, K. D. Pelzer, and M. J. Hawkins. 2001. Risk factors for clinical salmonellosis in Virginia, USA cattle herds. Prev. Vet. Med. 49:259-275.

Warnick, L. D., J. B. Kaneene, P. L. Ruegg, S. J. Wells, C. Fossler, L. Halbert, and A. Campbell. 2003a. Evaluation of herd sampling for Salmonella isolation on midwest and northeast US dairy farms. Prev. Vet. Med. 60:195-206.

Warnick, L. D., K. Kanistanon, P. L. McDonough, and L. Power. 2003b. Effect of previous antimicrobial treatment on fecal shedding of Salmonella enterica subsp. enterica serogroup B in New York dairy herds with recent clinical salmonellosis. Prev. Vet. Med. $56: 285-297$.

Wolf, C. A. 2003. Custom dairy heifer grower industry characteristics and contract terms. J. Dairy Sci. 86:3016-3022.

Wray, C., N. Todd, I. McLaren, Y. Beedell, and B. Rowe. 1990. The epidemiology of Salmonella infection of calves: The role of dealers. Epidemiol. Infect. 105:295-305.

Zansky, S., B. Wallace, D. Schoonmaker-Bopp, P. Smith, F. Ramsey, J. Painter, A. Gupta, P. Kalluri, and S. Noviello. 2002. From the Centers for Disease Control and Prevention. Outbreak of multidrug resistant Salmonella Newport-United States, January-April 2002. JAMA 288:951-953 